\title{
Evolutionary perspectives on human sex differences and their discontents
}

\author{
JULIEN DELHEZ* \\ Georg-August-Universität Göttingen, Eichweg 19, 37077 Göttingen, Germany
}

(Received: 15 March 2019; accepted: 03 May 2019)

\begin{abstract}
Evolutionary explanations of human behavior have produced many new insights, but also much resistance. This essay examines 2 books on sex differences written with very different approaches. Rosemary Hopcroft's Evolution and Gender argues that men and women can be both equal and different and that average biological differences between the sexes, which are often small, do not threaten the ideal of political equality. In Hopcroft's view, understanding these differences with the help of evolutionary theory is a condition for the realization of equality, not an obstacle. Saini's Inferior depicts an opposition between an 'old science', portraying sex differences as immense, and a 'new science', with most sex differences being so small that they cannot possibly account for social trends. While Evolution and Gender gives a concise and representative view of current evolutionary research on sex differences, Inferior claims that obsessions pervade entire research areas. Evolution and Gender has a careful tone, while Inferior often emphasizes the allegedly 'controversial' nature of studies. The essay ends with reflections on how to best communicate the results of evolutionary psychology to the public.
\end{abstract}

Keywords: evolution, human sex differences, sexual selection, personality, behavior, cognitive abilities, social equality

\section{INTRODUCTION}

Drawing on insights from many research fields, evolutionary psychology (EP) has provided powerful explanations for many aspects of human behavior, including human sex differences. EP draws on evolutionary theory and interspecies comparisons. A few central premises include that the costs of procreation and the certainty of relatedness to the offspring differ starkly between the sexes. These facts are conspicuously consistent with evolved psychological sex differences in mate choice preferences, strategies used in intra-sexual competition, and social and competitive behaviors in general (Geary, 2010).

The EP approach has faced resistance both in academe and in the public sphere. One reason is probably that many people fall prey to the naturalistic fallacy, assuming that those who describe the reality of nature also consider that to be desirable. Another reason may be that people subscribe to the blank slate view of human nature, because they reject the assumed determinism implied by any genetic influences on their psychology (Pinker 2002; Mali, 2017). But one may ask whether misunderstandings are the only problem. Do critics really challenge evolutionary psychology of today, or are they combating ideas about sex differences that have long been outdated? And what is the conceptual perspective of these critics?

In this article, I explore these evolutionary explanations in connection with examining 2 books: Rosemary Hopcroft's Evolution and Gender: Why It Matters for Contemporary Life (Hopcroft, 2016) and Angela Saini's Inferior:
How Science Got Women Wrong - and the New Research That's Rewriting the Story (Saini, 2017). There are certainly many other books that deal with sex differences, because of the upsurge of attention in the last decade or so. I have chosen these particular books because both deal with sex differences in general, are recent enough to reflect the latest debates on this issue, and have enjoyed significant attention and recognition (mostly academic for Evolution and Gender and mainly from journalists and part of the public at large for Inferior).

Rosemary Hopcroft is a professor in sociology who used to think that men and women are "equal and the same" but has since renounced her "youthful ideas" (Hopcroft, 2016: 3). She explained that evolution is crucial for understanding average sex differences and that "understanding average differences is key to the full realization of equality in healthcare and other dimensions of social life" (Hopcroft, 2016: I). Evolution and Gender was positively reviewed in the Yale Journal of Biology and Medicine (Beilinson, 2016) and received the Best Book Award from the division on Evolution, Biology, and Society of the American Sociological Association (2018).

Inferior often deals (albeit not exclusively) with evolutionary explanations of sex differences, including the recent ones. The key theme of Inferior is a contrast between

*Author for correspondence: Georg-August-Universität Göttingen, Eichweg 19, 37077 Göttingen, Germany, delhez.julien@gmail.com, +491712128513 .

This is an open-access article distributed under the terms of the Creative Commons Attribution-NonCommercial 4.0 International License (https://creativecommons.org/licenses/by-nc/4.0/), which permits unrestricted use, distribution, and reproduction in any medium for non-commercial purposes, provided the original author and source are credited, a link to the CC License is provided, and changes - if any - are indicated. 
an 'old science' having gotten women wrong and a 'new science' showing that there are few differences between the sexes. The 'old science' does not only include nineteenth-century myths about women, but "the scientific establishment has also painted a distorted picture of the female sex", which "has skewed how science looks and what it says even now" (Saini, 2017: 4). Saini explicitly criticized evolutionary psychology: "in some branches of science, such as evolutionary psychology, theories may be little more than thin scraps of unreliable evidence strung into a narrative" (Saini, 2017: 13). To the best of my knowledge, Inferior has not been reviewed in scientific journals to date, but was praised in influential outlets such as the Guardian (Davis, 2017), the Independent (Da Silva, 2017), and Scientific American (Gawryleski, 2017).

\section{HUMAN EVOLUTION: GENERAL PRINCIPLES AND SOCIAL IMPLICATIONS}

One cannot fairly assess evolutionary psychology without understanding two of its core concepts: natural selection and sexual selection. Many theories have something in common-they propose certain causal associations between higher-order constructs, without specifying the minute underlying mechanisms. This is also true of evolution, but it is generally accepted worldwide, on the good grounds that the predicted associations bear out. The explanatory power of sexual selection is, however, less known to the general public (Mota, 2009/2010).

Hopcroft neatly avoided this pitfall. In her introduction, she explained the core principles of evolutionary approaches to sex differences, including Robert Trivers' insight into "sex differences in fixed biological investment in offspring" (Hopcroft, 2016: VIII), human adaptations to the prehistoric environment of the Pleistocene, Richard Dawkins' gene-centric view of evolution, and Hamilton's Rule. Hopcroft (2016: 81-82) occasionally refers to the findings on other primate species and explains how the intensity of sexual selection relates to the magnitude of sex differences in these primate species.

In Inferior, key principles such as 'sexual selection' or 'evolutionary mismatch' are hardly presented. Granted, Saini acknowledged that primatologists, evolutionary psychologists, archeologists, and anthropologists can illuminate past sex roles:

"One window on the past is provided by primatologists studying our closest animal cousins, the great apes, from whom humans split around five million years ago. Studying how they interact gives us some insight into what our basic way of life may have been before we became the species we are now. Another window comes from evolutionary psychologists who try to picture life in the Pleistocene, the epoch that includes the time, roughly 200,000 years ago, when modern humans evolved looking anatomically the way we do now. Then there's archaeological evidence such as tools and bones. By observing the lives of modern-day hunter-gatherers, anthropologists can also draw portraits of how early woman might have lived." (Saini, 2017: 124).

But her perspective is essentially a comparative one. She wrote: "Judging humans by our patriarchal history, it's easy to see why so many primatologists have compared us to chimpanzees. But is it possible that somewhere in our evolutionary history we were matriarchal, as bonobos appear to be?" (Saini, 2017: 203). Obviously, singling out bonobos constitutes cherry-picking and ignoring the behavioral and physiological differences from other primates that are consistent with their social organization.

More importantly, Saini failed to acknowledge that evolutionary scientists have continuously revised their hypotheses. The limitations of Darwin's treatment of sexual selection have been highlighted by Robert Trivers (1972), and many have followed in his wake. Schmitt (2015) noted that "because so much evolutionary psychological research has been produced over the last 25 years it is hard for even evolutionary-informed scholars themselves to keep up" - hence, the persistence of misconceptions about evolutionary psychology. To conclude, one cannot accept Saini's simplistic dichotomy between a sexist 'old science' and an unprejudiced 'new science'. Hopcroft's book gives a fuller and more detailed account of today's evolutionary psychology, and one would be hard-pressed to find anything sexist in it.

\section{PHYSIOLOGY AND HEALTH DIFFERENCES}

To understand sex differences, one can use both proximal and ultimate explanations. Ultimate explanations include the selection of traits, favoring the replication of the genes that foster them. Proximal explanations include hormones and other endocrinological processes that are related to sex differences in behavioral tendencies and that may sometimes be inconclusive.

Hopcroft points out that, while men have an advantage for short-term, intense efforts (e.g., many sports), women live longer, on average, and have a stronger immune system. She wrote, both diplomatically and insightfully: "are women weaker than men, on average? The answer depends on what you mean by weaker" (Hopcroft, 2016: 110). Hopcroft noted that these differences correspond to the likely needs of both sexes in the Paleolithic environment: Hunters needed to make short and intense physical efforts, while caregivers had to be resilient in the long run. Hopcroft also discussed proximal factors such as hormones, noting that testosterone is associated not only with higher aggressiveness and status striving, but also with lower resistance to diseases. As for aggressiveness, Hopcroft cautiously wrote: "given the small associations between testosterone and aggression, it is likely that any causal relationship is also small" (Hopcroft, 2016: 157).

Saini agreed with Hopcroft that on average, women live longer while men have greater physical strength. There are two main differences with Hopcroft's approach. First, evolutionary explanations are completely absent in Saini's discussion of these differences. The causal factors she mentioned, including levels of progesterone and estrogen (Saini, 2017: 47), and the fact that having two X chromosomes protects women against a number of genetic diseases (Saini, 2017: 52), are all proximal factors. The second difference lies in the treatment of research on hormonal influences on behaviour: while Hopcroft presented 
a cautious account of recent research results, Saini told the story of endocrinologists' excessive excitement about testosterone and its purported links with aggressiveness in the 1920 s and in the 1930 s, followed by a reappraisal in the 1970s, and then very recent studies showing no link between testosterone and aggressiveness (Saini, 2017: 3237). Once again, the reader is presented with a strong contrast between 'old science' and 'new science.'

\section{PERSONALITY, BEHAVIOUR, AND MATE PREFERENCES}

It is now widely accepted among evolutionary psychologists that both males and females are interested in casual sex as well as in long-term relationships (Schmitt, 2015). The main difference between males and females consists of criteria for choosing either short-term or long-term partners.

Hopcroft (2016: 31-84) dedicated four chapters to this topic: female preferences for long-term mates, men's preferences for long-term mates, women and men's criteria for bodily beauty, and sex differences in short-term mating strategies.

Saini contended that both females and males can show interest in short-term relationships, but most evolutionary psychologists would be stunned by how she described sexual selection:

"At the heart of sexual selection theory, as it applies to humans at least, is the notion that men are promiscuous and undiscriminating, while women are highly discriminating and sexually passive. Females are choosy and chaste. It all comes down to Angus Bateman's principles, as demonstrated both by his flies and by Clark and Hatfield's human subjects on the campus of Florida State University in 1978. Men will sleep with strangers, while women simply won't." (Saini, 2017: 166).

Clearly, what she described is not present-day evolutionary psychology. Her indiscriminate description reflects a prejudice that David P. Schmitt personally experienced at a conference:

"When I tried to dispel this common misperception by noting, for instance, that evolutionary psychologists have hypothesized women are just as designed for short-term mating as men are-in some ways even more so such as women's heightened desires for cues to genetic quality in short-term mates - an audible gasp swept through the conference hall. [...] I asked an audience member near the front row who had her hand over her mouth if something was unclear, to which she proclaimed, "that's not the evolutionary psychology I know." When I tried to explain that women's evolved short-term mating desires have been studied by evolutionary psychologists since the early 1990s and the topic remains a very active area of inquiry today, heads swiveled in disbelief." (Schmitt, 2015; Schmitt's emphasis).

Let us turn to sex differences in behavior and personality. Hopcroft discussed sex differences in traits such as aggressiveness, criminality, and emotional responses. The following quote perfectly represents her perspective: "I want to stress that the evolved differences between the sexes described in this book are often (although not always) small differences. Yet even small differences can still have a noticeable effect on the aggregate patterns we see in society. I also want to stress that the sex differences I describe are average differences" (Hopcroft, 2016: IX). For her, both environment and evolved predispositions matter: "Evolved predispositions exist in our genetic makeup as humans, but this does not mean that everything we do is determined by them [...]. Behavior is always a product of a particular predisposition and the environment of the individual at the same time" (Hopcroft, 2016: 10).

Such nuanced views are absent when Saini discussed secular changes in sex differences in mathematics: "If mathematical ability was rooted in biology, and sex differences were fixed, then we wouldn't expect to see these kinds of changes over times. What's more, we would expect the differences to be the same everywhere. And they're not" (Saini, 2017). After discussing international differences, including countries where boys outperform girls in mathematics, she wrote: "What looks like a biological difference in one particular place and time, can turn out to be a cultural difference after all" (Saini, 2017: 118). This gives the impression that, for Saini, it's either biology or culture, not both.

Nor does the author of Inferior describe modern research as promoting the idea of small average differences that nonetheless have social implications. In her introduction, Saini wrote:

"Sex differences is today one of the hottest topics in scientific research. An article in the New York Times in 2013 stated that scientific journals had published thirty thousand articles on sex differences since the turn of the millennium. Be it language, relationships, ways of reasoning, parenting, physical and mental abilities, no stone has gone unturned in the forensic search for gaps between women and men. And the published work seems to reinforce the myth that those gaps are huge." (Saini, 2017: 12).

This recent research is included in Saini's 'old science' due to its alleged role in promoting the idea of large sex differences. The author also writes: "Today, away from the barrage of questionable research on sex differences, we have a radically new way of thinking about women's minds and bodies. Fresh theories on sex differences, for example, suggest that the small gaps that have been found between the brains of women and men are merely statistical products of the fact that we are all unique" (Saini, 2017: 13). Note her usage of the word 'merely, which downplays the significance of these differences. Again, as Hopcroft writes, all scientists should know that even small average differences can "have a noticeable effect on the aggregate patterns we see in society" (Hopcroft, 2016: IX).

\section{COGNITIVE DIFFERENCES}

Sex differences in cognitive abilities have been discussed in numerous textbooks. While some consensus has been reached over specialized abilities, there has been much recent discussion on 2 issues: whether the sexes differ in $g$, 
the general intelligence factor, and whether they differ in IQ defined as the aggregate of all cognitive abilities (fullscale IQ or FSIQ). These issues, whose complexity should not be understated, appear less settled than they were at the end of the twentieth century (Geary, 2010: 411-412; Hunt, 2010: 375-382; van der Linden, Dunkel \& Madison, 2017). All participants in the debate need to grasp at least the most basic elements of differential psychology, especially notions about IQ, $g$, specialized abilities, and how to assess each type of cognitive ability.

Hopcroft dedicates a chapter of her book to cognitive sex differences (pp. 113-129). She mainly discussed differences that are recognized by most scientists, e.g., in specialized abilities and in the statistical distribution of intelligence, with a higher proportion of males at both extremes of the bell curve. She also suggested evolutionary explanations for these differences. While she wrote-note the careful wording - that "[i]ntelligence tests were designed so that men and women, on average, have equal IQs" (Hopcroft, 2016: 122), she did not address the issue of sex differences in $g$. This may be due to the author's desire to keep her book accessible to a wide audience. Admittedly, this topic may be too technical and require explanations about statistical methods such as factor analysis, the $g$ loading of subtests, the method of correlated vectors (see Jensen, 1998: 143-145), and what a 'Jensen effect' is (see Rushton, 1998: 217).

In Saini's view, there are simply no substantial sex differences in any cognitive ability: "Study after study has shown almost all behavioural and psychological differences between the sexes to be small or non-existent. Melissa Hines and others have repeatedly demonstrated that boys and girls have very little, if any, noticeable gaps between them when it comes to fine motor skills, spatial visualisation, mathematical ability and verbal fluency" (Saini, 2017: 110). Again, students of group differences are well aware that gaps can be both small and noticeable and that they can have nontrivial social consequences. Since many sex differences emerge at puberty, it is important to account for this distinction and to avoid obscuring differences by aggregating boys and men and girls and women.

Even more problematic is the way Saini write about the $g$ factor: "When it comes to intelligence, too, it has been convincingly established that there are no differences between the average woman and man. Psychologist Roberto Colom at the Autonomous University of Madrid found negligible differences in 'general intelligence' (a measure that takes into account intelligence, cognitive ability and mental ability)" (Saini, 2017: 85). Not realizing that 'intelligence' broadly speaking includes both $g$ and specialized abilities, Saini misunderstood Colom's position, which is that the sexes do differ in intelligence but not in $g$ (Colom et al., 2000; this position was reiterated in Colom, 2017). How can Saini wrote about sex differences in intelligence without grasping such an elementary concept of intelligence research as the $g$ factor and without being able to distinguish it from specialized abilities and from 'intelligence' broadly speaking? (In addition, it is objectionable to base an assertive claim like that on a single study, and not a meta-analysis.)

\section{THE EVOLUTIONARY ORIGINS OF PATRIARCHY}

Evolution helps understand virtually all aspects of human societies. This includes mate-guarding (Buss, 2002) and the emergence of patriarchal organization (Smuts, 1995).

Saini acknowledges a link between sexual jealousy and patriarchy, but instead of seeing the former as causing the latter, she thought their interaction resulted in repression of women's sexuality and autonomy. Noting that "[s] exual jealousy and mate-guarding are powerful biological drives, seen throughout the animal kingdom," she suggested: "If behaviour like this had been exaggerated by humans, woven into society and culture, it might explain why women now appear to behave as modestly as they do" (Saini, 2017: 188). But she saw patriarchy itself as the result of cultural evolution and, in agreement with Friedrich Engels and author Gerda Lerner, as an outcome of historical and economic processes. Since she acknowledged "the biological drive that men have to jealously guard females from other males" (Saini, 2017: 195), an important question remains unanswered. Where did this biological drive come from? In addition, why is sexual jealously more pronounced for men than for women?

Hopcroft (2016: 52-55) points out a crucial difference between men and women: only the latter are always $100 \%$ sure that the child that comes out of their womb is theirs. Due to paternity uncertainty, it is no wonder that, according to a cross-cultural study by Buss et al. (1990), "no previous sexual experience in a prospective marriage partner was a more important criteria for men (rated 1.06 on a three-point scale) than for women (rated 0.75 on a threepoint scale)" (Hopcroft, 2016: 53). This, Hopcroft explained, helps in understanding the recurrent emergence of "rules and practices that serve to control the sexuality of women (but not men)" (Hopcroft, 2016: 54), as well as the emergence of ideologies arguing that females cannot be left on their own (Hopcroft, 2016: chapter 7).

As for whether humans were matriarchal in the past, Saini (2017: 203) raised the possibility that our societies might have been similar to that of bonobos, not chimpanzees. The crucial difference is that unlike bonobos, humans have concealed ovulation. As Grant and Montrose (2018: 384) pointed out: "Signs of estrus in human females are much subtler than in many other species meaning that there is less certainty of the exact timing of the fertile period. This necessitates extended mate guarding which potentially reduces male fitness due to the loss of extra-pair fertilization and other fitness-compromising costs, such as reduction in the time spent acquiring status and resources." Grant and Montrose suggested that patriarchal measures such as foot-binding, chastity belts, and female genital mutilations, as well as other explicit or implicit rules, aim at reducing the costs and the time men had to spend in mateguarding. Grant and Montrose also suggested that biological evolution favored predispositions for sexual jealousy among males, insofar as jealous males were less likely to be cuckolded by females. This is a conclusion Saini could have reached on the basis of her own observation that in Mali, where Dogon women are secluded in menstrual huts, paternity tests showed that "men who followed the 
traditional Dogon religion were four times less likely to be cuckolded than Christian men, whose wives didn't use the huts" (Saini, 2017: 188). Here, I want to stress (with Hopcroft) that suggesting the existence of evolved predispositions for some traits does not make these traits acceptable. In my view, it is often by understanding the roots of our worst tendencies that we can learn to overcome them.

\section{DISCUSSION}

An overview of these two books would not be complete without a discussion of their tone, which especially matters for such a sensitive topic. Hopcroft insisted that sex differences are often small average differences, and far from seeing them as explaining all social trends, she wrote "that discrimination against women occurs in the workplace and in many other areas of life" (p. IX), She also addressed misconceptions about evolution, e.g., the idea that evolved predispositions mean determinism, that nothing can be done to override them, or that what is natural is necessarily good (Hopcroft, 2016: 11). Finally, she warned against temptations of offering a yes-or-no answer to simplistic questions, e.g., whether women are the smarter sex: "If you prioritize one set of cognitive skills, then women are smarter. If you prioritize a different set of cognitive skills, then men are smarter" (Hopcroft, 2016: 114). By contrast, Saini preferably used emotionally charged words: "Studies into sex differences are as powerful as they are controversial" (Saini, 2017: 37); "Research into sex differences has an ugly and dangerous history" (Saini, 2017: 64); "this is a world in which even cold, rational scientists can't abandon their desire to hunt for differences between women and men" (Saini, 2017: 95); "Brain researchers have never been able to resist the urge to scour the skulls of women and men in search of variation" (Saini, 2017: 96). Some accusations are too imprecise to be constructive. For instance, Saini wrote that recent research leaves a picture "very different from that of the sedentary, weak and dependent woman that some evolutionary biologists have painted in the past" (Saini, 2017: 147; my emphasis). Even more hazy: "I'm told that psychology professor Melissa Hines is one of the most balanced and fair researchers in her discipline - which is important in a field that is sometimes not balanced, not fair" (Saini, 2017: 81). While researchers often benefit from listening to those who disagree with them, innuendos and vague claims such as these will certainly not help.

The books Evolution and Gender and Inferior tell us much about how to improve debate on sex differences. Debaters from all sides should grasp the principles of Darwinian evolution and be able to criticize evolutionary psychology for what it is, not a dated or a straw-man version of it. The ability to identify the naturalistic fallacy and other sophisms is also crucial. Hopcroft gave a precious insight into the evolutionary reasons for patriarchy, while also pointing out that humans can say 'no' to their biological imperatives. Her overview of sex differences will benefit all those who think it is better to "be aware of these tendencies and learn to deal with them than to pretend they don't exist" (Hopcroft, 2016: 244).
Hopcroft's warnings against the naturalistic fallacy are much needed. On this matter, it is worth examining a passage where Saini wrote that "equality isn't just a political ideal, but every woman's natural, biological right" (Saini, 2017: 14). She seemed to accept the concept of "natural right," a concept implying that the principles of the natural and physical world (the 'laws of the universe') tell us not only what is, but also what ought to be. From the very beginning, Inferior is jeopardized by this view, which badly encumbers the debate on sex differences and the evolutionary reasons for them. Unless evolutionary psychologists, personality researchers, and intelligence researchers take the time to respond to such critics, books like Inferior will create much confusion and will seriously deteriorate the dialogue between the public and the scientific community.

\section{CONFLICT OF INTEREST}

The author declares that the present work was prepared in the absence of any financial, professional or personal relationship with either author whose work is addressed here.

\section{REFERENCES}

American Sociological Association (2018). Awards: 2018 recipients. Best Book Award. Retrieved from http://www. asanet.org/asa-communities/sections/sites/evolution-biologyand-society/awards/.

Beilinson, H. A. (2016). Review of Rosemary L. Hopcroft, Evolution and Gender: Why It Matters for Contemporary Life. New York and London, Routledge. Yale Journal of Biology and Medicine. 89, 273.

Buss, D. M. (2002). Human mate guarding. Neuroendocrinology Letters. 23, 23-29.

Buss, D. M. et al (1990), International Preferences in Selecting Mates: A Study of 37 Cultures. Journal of Cross-Cultural Psychology. 21, 5-47.

Colom, R. (2017). Counting is not Measuring: Comments on Richard Lynn's Developmental Theory of Sex Differences in Intelligence. Mankind Quarterly. 58, 69-75.

Colom, R., Juan-Espinosa, M., Abad, F. \& García, L. F. (2000). Negligible Sex Differences in General Intelligence. Intelligence. 28, 57-68.

Da Silva, C. (2017). Inferior by Angela Saini, book review: An enlightening account that shatters gender stereotypes. The Independent, May $24^{\text {th }}$, 2017. Retrieved from https://www. independent.co.uk/arts-entertainment/books/reviews/inferiorangela-saini-book-review-sexism-women-men-a7752206.html.

Davis, N. (2017). Inferior: How Science Got Women Wrong by Angela Saini - review. The Guardian, June $6^{\text {th }}, 2017$. Retrieved from https://www.theguardian.com/books/2017/jun/ 06/inferior-how-science-got-women-wrong-angela-saini-reviewand-the-new-research-thats-rewriting-story.

Gawryleski, A. (2017). Daring Apollo 8 Astronauts, Rediscovering a Forgotten Math Genius and Other New Science Books. Scientific American. 316, 74. Retrieved from https://www.scientificamerican.com/article/daring-apollo-8astronauts-rediscovering-a-forgotten-math-genius-and-othernew-science-books1/. 
Geary, D. (2010). Male, Female: The Evolution of Human Sex Differences. $2^{\text {nd }}$ edition. Washington, DC: American Psychological Association.

Grant, R. A. \& Montrose, V. T. (2018). It's a Man's World: Mate Guarding and the Evolution of Patriarchy. Mankind Quarterly. 58, 384-418.

Hopcroft, R. (2016). Evolution and Gender: Why It Matters for Contemporary Life. New York and London: Routledge.

Hunt, E. (2010). Human intelligence. Cambridge: Cambridge University Press.

Jensen, A. R. (1998). The $g$ factor. Westport, CT: Praeger.

Mali, M. (2017). 15 years later, why do we still believe in the blank slate? Areo Magazine, August 2, 2017. Retrieved from https://areomagazine.com/2017/08/02/15-years-later-why-dowe-still-believe-in-the-blank-slate/.

Mota, P. G. (2009/2010). Darwin's sexual selection theory - a forgotten idea. Antropologia Portuguesa. 26/27, 149-161.

Pinker, S. (2002). The Blank Slate. The Modern Denial of Human Nature. New York: Viking Penguin.
Rushton, J. P. (1998). The "Jensen effect" and the "SpearmanJensen hypothesis" of black-white IQ differences. Intelligence. 26, 217-225.

Saini, A. (2017). Inferior: How Science Got Women Wrong-and the New Research That's Rewriting the Story. London: $4^{\text {th }}$ Estate.

Schmitt, D. P. (2015). "Yes, but..." Answers to Ten Common Criticisms of Evolutionary Psychology. The Evolution Institute, April 12 ${ }^{\text {th }}, 2015$. Retrieved from https://evolutioninstitute.org/on-common-criticisms-of-evolutionary-psychology/.

Smuts, B. (1995). The evolutionary origins of patriarchy. Human Nature. 6, 1-32.

Trivers, R. L. (1972). Parental Investment and Sexual Selection. In: Campbell, B. (ed.), Sexual Selection and the Descent of Man, 1871-1971. New York, NY: Aldine, 136179.

Van der Linden, D., Dunkel, C. S. \& Madison, G. (2017). Sex differences in brain size and general intelligence $(g)$. Intelligence. 63, 78-88. 